\title{
Perceived risk, Positive Youth-Parent Relationships, and Internalizing Problems in Adolescents: Initial Development of the Meaningful School Questionnaire
}

\author{
Gökmen Arslan ${ }^{1}$ [ $\cdot$ Murat Yıldırım²
}

Accepted: 5 July 2021 / Published online: 12 August 2021

(c) The Author(s), under exclusive licence to Springer Nature B.V. 2021

\begin{abstract}
This novel paper aimed to develop the Meaningful School Questionnaire (MSQ) to assess meaning in life in school context and examined whether meaningful school serves as a moderator on the links between the coronavirus risk, youth-parent relationships, and internalizing problems. Participants included 383 adolescents $(38.4 \%$ male; Mean $=14.23 \pm 2.04$ ). Factor analysis yielded a two-factor solution: purposeenjoyment and responsible understanding. Meaningful school moderated the mediating effect of positive youth-parent relations on the association between coronavirus risk and internalizing problems. Findings suggest that students with greater life meaning exhibit more internalizing problems when coronavirus risk is high and positive youth-parent relationships is low. This evidence supports that life meaning is key to foster the psychological health of young people during the pandemic. Thus, meaning-based intervention strategies could be developed to improve youths' sense of life meaning and purpose in the school context, which in turn enhance their resilience to foster their mental health and flourishing. These programs could facilitate youths to cope with stressful experiences such as the coronavirus pandemic by promoting their protective and promotive resources.
\end{abstract}

Keywords Meaningful school · Coronavirus risk · Positive youth-parent relationships $\cdot$ Internalizing problems $\cdot$ Adolescents

By April 1, 2020, 172 countries have implemented country-wide school closures, which has globally affected nearly 1.4 billon students, to prevent the spread of the COVID-19 pandemic (UNESCO, 2020). School closures intervention has also been

Gökmen Arslan

gkmnarslan@gmail.com

1 Department of Psychological Counseling and Guidance, Mehmet Akif Ersoy University, Burdur, Turkey

2 Department of Psychology, Ağrı İbrahim Çeçen University, Ağrı, Turkey 
implemented in times of previous epidemics and pandemics like the global pandemic of H1N1 influenza virus in 2009. School closures as a non-pharmaceutical prevention approach has received important attention from the public health research community, policy makers, the public and the media (Cauchemez et al., 2014). School closures can help to reduce the transmission and incidence of COVID-19 pandemic in school-aged children by $40-60 \%$ and delay the pandemic (Zhang et al., 2020). However, little is known how COVID-19 effects children and young people (Burke \& Arslan, 2020; Cowling et al., 2020). Recent studies have reported that school closures have impacted mental health of school-aged children including lengthened state of physical isolation from peers, teachers, extended family, and community networks (Loades et al., 2020; Xie et al., 2020). In a study conducted during COVID19 among Chinese students, high prevalence rates of depression $(22.6 \%)$ and anxiety (18.95\%) have been reported in comparison to prior to pandemic (Xie et al., 2020) and researchers concluded that these high rates of mental health problems could be associated with reduction in social interaction and outdoor activities. Another study conducted in Turkey reported that prolonged closures of schools and homequarantine during the COVID-19 pandemic have detrimental effects on the physical and mental health of young people and exposing adolescents to exclusive negative content information related to COVID-19 results in increased levels of anxiety and stress (Kılınçel et al., 2020).

The conception of risk is a complex, psychically oriented, and socially formed phenomenon and can defined as one's psychological assessment of hazardous objects, events or activities (Slovic et al., 1982). A wide range of factors can affect risk perception such as probability, severity, controllability, dread, catastrophic potential, and unfamiliarity with a hazard (Arslan, 2021; Renn \& Rohrmann, 2000; Slovic, 1987). Evidence from previous pandemic like SARS and avian influenza suggest that risk perception is related to implementation of health-related protective factors such as social and physical distancing (Genç \& Arslan, 2021; Caley et al., 2008) and frequent handwashing and avoidance of hand-shacking (Leppin \& Aro, 2009). Available information from the current COVID-19 pandemic demonstrates that higher level of risk of COVID-19 is related to higher level of COVID-19 severity and lower levels of perceived self-efficacy and mental health (Yıldırım \& Güler, 2020).

\section{Youth-Parent Relationships and Meaningful School}

Adolescents-parent relationships is conceptualized as a multidimensional concept that refers to an emotional "atmosphere" in the relationships between the parent and the adolescent (Wissink et al., 2006). The concept includes three different yet related components: positive quality relationship, negative quality relationship, and disclosure (Erdem, 2017; Wissink et al., 2006). Adolescents-parent relationships have been demonstrated to be one of the contributing factors various mental health problems (Wang et al., 2014). Quality of parent-adolescent relationships have been found to be associated with different psycho-social and behavioural problems in adolescents. For example, Eichelsheim et al. (2010) reported that disclosure, perceived 
parental support, and autonomy granting by parents were significantly negatively associated with aggression and delinquency while negative quality of parent-child relationship was significantly positively associated with both aggression and delinquency in different ethnic groups such as Turkish, Surinamese, and Antillean. Also, quality of parenting relationships was related with various externalizing problems such as antisocial behaviors and deviant peer associations (Wissink et al., 2006). Furthermore, siblings and parent-child relationship quality were associated with internalizing and externalizing problems (Buist et al., 2017). Although limited, the relationship between parent-child relationships with meaning in life has been documented. In a study, positive parent-child relationships were linked to familism, internalizing and externalizing symptoms, and meaning in life, and academic motivation (Stein et al., 2020).

According to Frankl (1984), search for meaning in life is the basic and most powerful motivation in one's life. He also argued that meaning in life can only be discovered when people engage in what they have learned about themselves in their lives, and distancing away from selfishness. The ultimate meaning of human existence can be found through philosophical reflections, religious beliefs, and psychological integration, alongside commitment, engagement, and the pursuit of life goals in everyday living (Wong, 1998). Considering the PURE theoretical model (see Wong, 2010 for more information), we here conceptualize meaningful school as a sense of purpose, enjoyment, and responsible understanding of life meaning in school context. Meaningful school is student's appraisal of their school life, reflecting acknowledging the intrinsic value of life and meaningful relationships and achievement in school. Young people with a high sense of meaning in school perceive school life as significant, purposeful, enjoyable, responsible, and valuable. There is evidence showing that meaning in life can protect psychological health of young people in times of adversity (Arslan et al., 2020). According to Arslan et al. (2020), people can still fulfil their lives by focusing on their own essence of searching for meaning in life even under difficult situations.

Research suggests that meaning in life is significantly positively associated with positive human functioning, subjective well-being, psychological well-being, and significantly negatively related to depression, anxiety, and distress (Platsidou \& Daniilidou, 2021; Jim \& Andersen, 2007; Kleftaras \& Psarra, 2012; Zika \& Chamberlain, 1992). Studies on young people have shown that young people tend to search for more meaning in life (Steger et al., 2011). Lack of meaning in life among young people are at risk of experiencing more mental health problems and poor psychological and physical health (Brassai et al., 2011). During a public health crisis, uncertainty and fear can cause people to feel stress, depressive, and anxiety over the direction of their life (Arslan \& Yıldırım, 2021), which in turn increase meaninglessness in life. Therefore, there is a need to shift focus from the risk factors to protective factors of mental health and wellbeing during adversity. Meaning in life is an important mechanism to protect individual's mental health and improve resilience to successfully overcome adversities (Yıldırım et al., 2021). Within the risk and protective theoretical framework, the capacity of young people to be resilient helps them to deal with significant negative circumstances and to maintain positive development within the context of these experiences (Luthar et al., 2000; Masten, 2014). Thereby, various protective factors are identified to 
buffer the impacts of adversities on young people's psychosocial outcomes (Arslan \& Y1ldırım, 2021; Arslan, 2018a, 2018b; Brassai et al., 2011; Deković, 1999). A sense of meaning in life has been emphasized to be a protective and promotive factor for healthy youth development and wellbeing (Arslan \& Allen, 2021; Brassai et al., 2011; Wong $\&$ Wong, 2012). A strong sense of meaning in life helps young people to understand themselves, the world around them, and their fit within the world (Brassai et al., 2011). Thus, an individual's sense of meaning in school life may serve as a resilience factor through influencing to engagement in developing and maintaining coping strategies and goals that promote a reduction in anxiety and depressive symptoms in face of adversity (August \& Dapkewicz, 2020; Arslan \& Yildırım, 2021).

One's level of meaning in life may impact willingness to engage in pursuing and achieving of rewarding goals that foster a reduction in depressive symptoms and stress in times of crisis. That is, promoting the meaningful living of individuals who experience meaninglessness crisis is important to improve psychosocial health, well-being, coping, and meaningful living as well as reducing symptomatology and meaninglessness in difficult times (Glaw et al., 2017).

There is a need for an index of meaning in life that particularly taps onto sense of meaning in life in young people. It facilitates the assessment of personal meaning in life and its relation to psychological, social and behavioral consequences. According to Steger et al. (2006), thus far, most studies have utilized one of three assessment tools: the Purpose in Life Test (Crumbaugh \& Maholick, 1964), the Life Regard Index (Battista \& Almond, 1973), or the Sense of Coherence-Meaning Scale (Antonovsky, 1987). Meaning in Life Questionnaire (Steger et al., 2006) is also commonly used as an index of presence of and search for meaning in life. However, none of the scales noted above exclusively captures youths' sense of meaning in life in school context. Accordingly, we aimed to develop a new measure of meaning in life that reflects youths' sense of purpose-enjoyment and responsible understanding of meaning in life in school context. Existential approach (Frankl, 1984, 1992; Wong, 1998, 2011), was deemed to be a useful basis for the development of the new scale.

Considering the literature and theoretical framework presenting above, the present study has two overarching goals. First, we aimed to develop a multidimensional scale of life meaning in school context named Meaningful School Questionnaire (MSQ) with robust evidence of reliability and validity that assesses purpose, understanding, responsibility, and enjoyment. Second, we sought to examine whether life meaning in school serve as a moderator on the mediating effect of positive youth-parent relationships on links between the coronavirus risk and internalizing problems in Turkish young people, as shown in Fig. 1. Based on these research questions, we hypothesized that (i) the MSQ would be a reliable and valid measure, and (ii) meaningful school would moderate the mediating effect of positive youth-parent relations on the association between coronavirus risk and internalizing problems. 

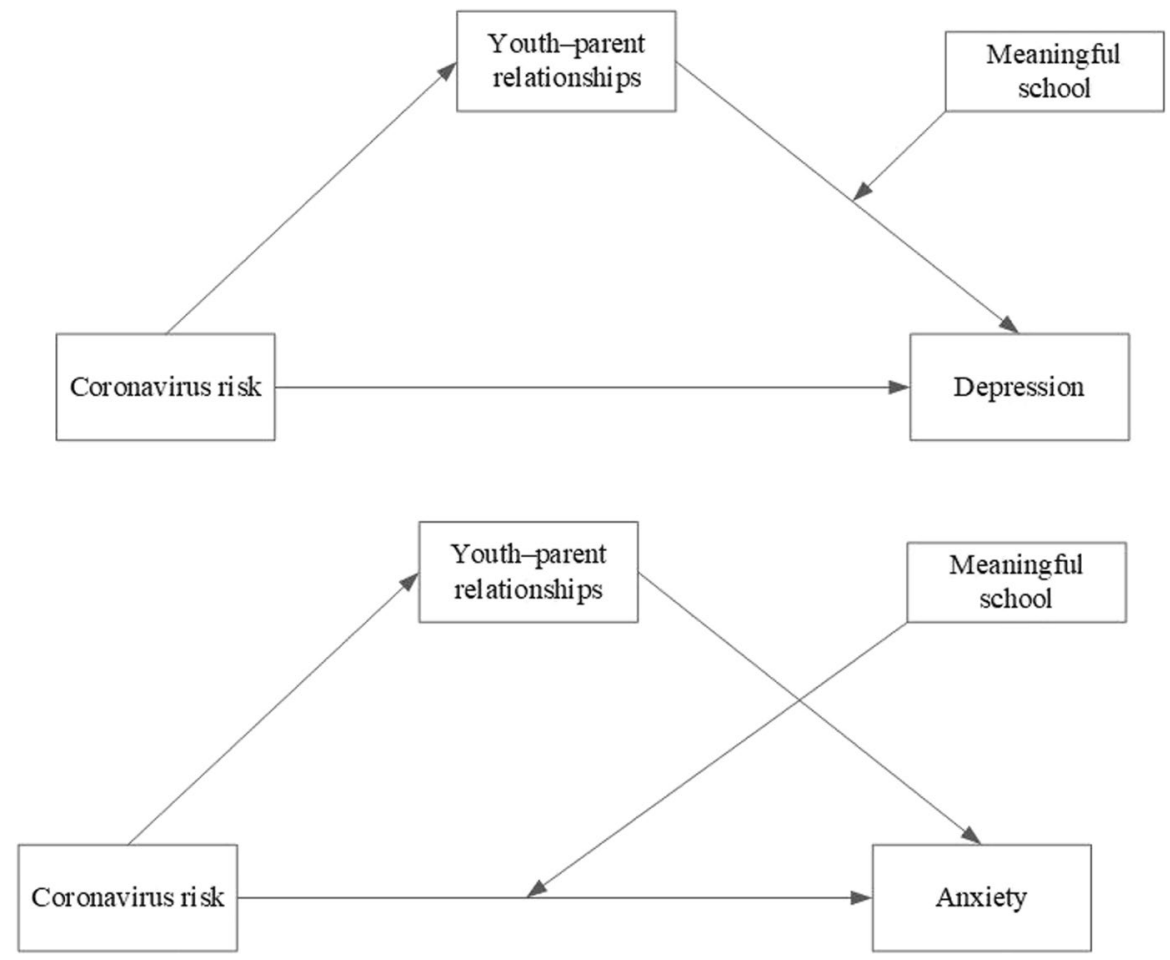

Fig. 1 Proposed models showing the association between the variables of the study

\section{Method}

\subsection{Participants}

Participants in the present study comprised of 383 young people ranging in age between 10 and 18 years $($ Mean $=14.23, S D=2.04)$. Young people were $38.4 \%$ male and $46 \%$ elementary school students. A web-based online survey was generated using demographic items and the measurement tools of the study. The study was approved by Ethic Committee of xxx University (blind review) before starting the data collection of the study. Participants were additionally informed that their participation in the study was voluntary, they could quit the survey at any time if they did not want to continue, and the survey was confidential. Data was collected between 20 October and 5 November 2020 during the pandemic. Prior to collecting the data, an electronic informed parental consent and assent form, as the first page of the survey, was signed by parents and young people who volunteered to participate in the study. 


\subsection{Measures}

\subsubsection{Meaningful School}

Although there are several measures available to assess life meaning in adults, to the best of our knowledge, there is no available scales that explicitly focus on young people' sense of life meaning in school setting. To this end, we developed the Meaningful School Questionnaire (MSQ) for the purpose of current study. Based on the PURE model (Wong, 2010), a series of discussions with the researchers working in meaningful living, and a review of the relevant literature, we generated 16 items -4 pilot items for each construct: purpose $(\mathrm{P})$, understanding $(\mathrm{U})$, responsibility $(\mathrm{R})$, and enjoyment (E). After generating the pilot items, a group of two professors in the fields of working in positive psychology of meaning in life, examined the MSQ item pool. Based on their feedback, some revisions were made on 7 items to increase clarity. All pilot items of the MSQ were scored on a 5 -point Likert type scale $(1=$ strongly disagree to $5=$ strongly agree $)$. Findings from these analyses (see the results section) suggest that MSQ is a reliable and valid scale for use to assess life meaning in school among Turkish samples.

\subsubsection{Coronavirus Risk}

COVID-19 Perceived Risk Scale was used to assess risk perception related to COVID-19 (Yıldırım \& Güler, 2020). The scale includes 8 items ("What is the likelihood that you would acquire the COVID-19?") that are rated on a 5-point Likert type scale varying from 1 (negligible) to 5 (very large). The scale has two dimensions of perceived risk: emotional dimension and behavioural dimension. An overall score can also be obtained by summing two dimensions. Higher scores indicate greater risk associated with the virus. For the purpose of this study, we selected only three items.

\subsubsection{Positive Youth-Parent Relationships}

Quality of the Parent-Adolescent Relationship Scale was used to measure the quality of parent-adolescent relationships and the parental child-rearing styles (Wissink et al., 2006). The scale comprises of 18 items ("How good is your relationship with your parent?") clustered into three dimensions (6 items per dimension): Disclosure, positive quality of parent-adolescent relationship, and negative quality of parent-adolescent relationship. We only selected the positive quality of parent-adolescent relationship. Each item is answered on a 5-point Likert scale type ranging from 1 (nothing) to 5 (everything). Duru et al. (2014) examined the adequacy of the measure with Turkish adaption of the scale, indicating a adequate internal reliability estimate. 


\subsubsection{Internalizing Problems}

Youth Internalizing Behavior Screener (Arslan, 2020) was used to assess the internalizing problems. The scale includes 10 items (e.g., "I have difficulty in relaxing and calming down myself.") rated on a 4-point Likert type scale ranging from 1 (almost never) to 4 (almost always). Higher scores indicate greater emotional problems. The scale provided adequate psychometric properties for use in assessing emotional challenges of Turkish young people (Arslan et al., 2020).

\subsection{Data Analyses}

Prior to performing the moderated mediation analysis, the factor structure and psychometric properties of the Meaningful School Questionnaire (MSQ) were examined using exploratory and confirmatory factor analysis. The study sample was randomly divided into two sub-samples (approximately 50\%; Sample 1: $N=191$ [with ranging in age from 10 to $18 ; M=14.21, S D=1.97$ ]; \%; Sample 2: $N=192$ [with ranging in age from 10 to $18 ; M=14.24, S D=2.11]$ ). The first sample was used to conduct exploratory factor analysis, and confirmatory factor analysis using maximum likelihood estimation carried out with the second sample. Exploratory factor analysis results were evaluated using factor loading $(\geq 0.55)$, cross-loading $(\geq 0.32)$, eigenvalues (values $>1$ ), visual inspection of the scree plot, and parallel analysis (O'Connor, 2000; Stevens, 2009). After exploring the factor structure of the measure, we performed a second-order confirmatory factor analysis to test the measurement model. Some model fit statistics and their decision rules were examined to evaluate the results of measurement model: CFI and TLI scores $0.95 \leq=$ good or close model fit; RMSEA and SRMR values $\leq 0.5=$ good or close model fit (Hooper et al., 2008; Kline, 2015).

Further, we investigated descriptive statistics and analysis assumptions. Skewness and kurtosis scores were used to examine the assumption of normality (Field, 2009; Tabachnick \& Fidell, 2013). The internal reliability estimates of the study measures were investigated with the sample of the study. To examine the association between study variables, correlation analysis was additionally employed. After reviewing these analyses, two independent moderated mediation models were conducted using the PROCESS macro (Model 5 and Model 14) for SPSS version 3.5 (Hayes, 2018). Within this approach, the moderation and mediation analysis are conducted together in a single model (Preacher et al., 2007). Research also suggests to follow the bootstrapping procedure because of advantageous this approach (Hayes, 2018; Preacher \& Hayes, 2008). Therefore, we interpreted the indirect effects using the bootstrap approach with 10,000 resamples to estimate the $95 \%$ confidence. All study analyses were carried out using SPSS version 25 . 


\section{Results}

\subsection{Factor Structure of the MSQ}

Exploratory factor analysis was conducted to examine the factor structure of the measure using the principal-axis factoring method (Promax rotation). Results from the factor analysis revealed a two-factor structure with eigenvalues $>1$, explaining $63.26 \%$ of the variance, with an adequate sample size (Kaiser-Meyer-Olkin test of sampling adequacy $=0.95$ ) and lack of singularity (Bartlett's $\left.\chi^{2}=2665.55, d f=136, p<0.001\right)$. After examining the pattern matrix, six items were excluded from the analyses due to low factor leadings (two items $<0.55$ ) and cross-loading (four items $\geq 0.32$ ), and the exploratory factor analysis was rerun. Parallel analysis and visual inspection of the scree plot also suggested a two-factor solution would be a good fit to the data. Finding from further factor analysis provided the two-factor solution that comprised of 10 items accounted for $62.89 \%$ of the variance, with strong factor loading, ranging between 0.60 and 0.95 , with no cross-loadings (scores $<0.25$ ), as shown in Table 1 .

We next performed the second-order confirmatory factor analysis to affirm the factor structure of the measure identified with exploratory factor analysis. Results from the analysis indicated a close data-model fit to the two-factor measurement model with 10 items that were indicators of two first-order latent structures (i.e., responsible understanding and purpose/enjoyment) $-\chi^{2}=54.02, d f=34$, $p=0.016, \mathrm{CFI}=0.98, \mathrm{TLI}=0.97, \mathrm{SRMR}=0.039$, RMSEA $(95 \% \mathrm{CI})=0.055$ $(0.024,0.082)$. The scale and its subscales had strong factor loadings, and the loadings ranged between 0.62 and 0.82 , as shown in Table 1 . The scale also provided strong reliability estimates $(\alpha$ range $=0.88-0.92 ; H$ range $=0.85-0.87$; $\mathrm{CR}=0.84-0.86$ ) and adequate convergent validity (AVE $>0.50$ and $<\mathrm{CR}$; see Table 1). Findings from these initial analyses provide evidence demonstrating that the MSQ has psychometrically adequate properties for assessing school-specific life meaning among elementary and high school Turkish students.

\subsection{Descriptive Statistics and Correlations}

Findings from descriptive statistics revealed that skewness values were between -1.60 and 1.25 , and kurtosis values ranged from -0.62 to 3.54 . These results suggest that all measures in the study were relatively normally distributed. Moreover, correlation analysis results showed that coronavirus risk perception had significant and negative correlations with positive youth-parent relationships and meaning, as well as positive correlations with depressive symptoms and anxiety. Student meaning was also significantly and positively associated with positive youth-parent relationships and had negative correlations with depressive symptoms and anxiety. Similarly, positive youth-parent relationships were significantly correlated with depressive symptoms and anxiety, as shown in Table 2. 


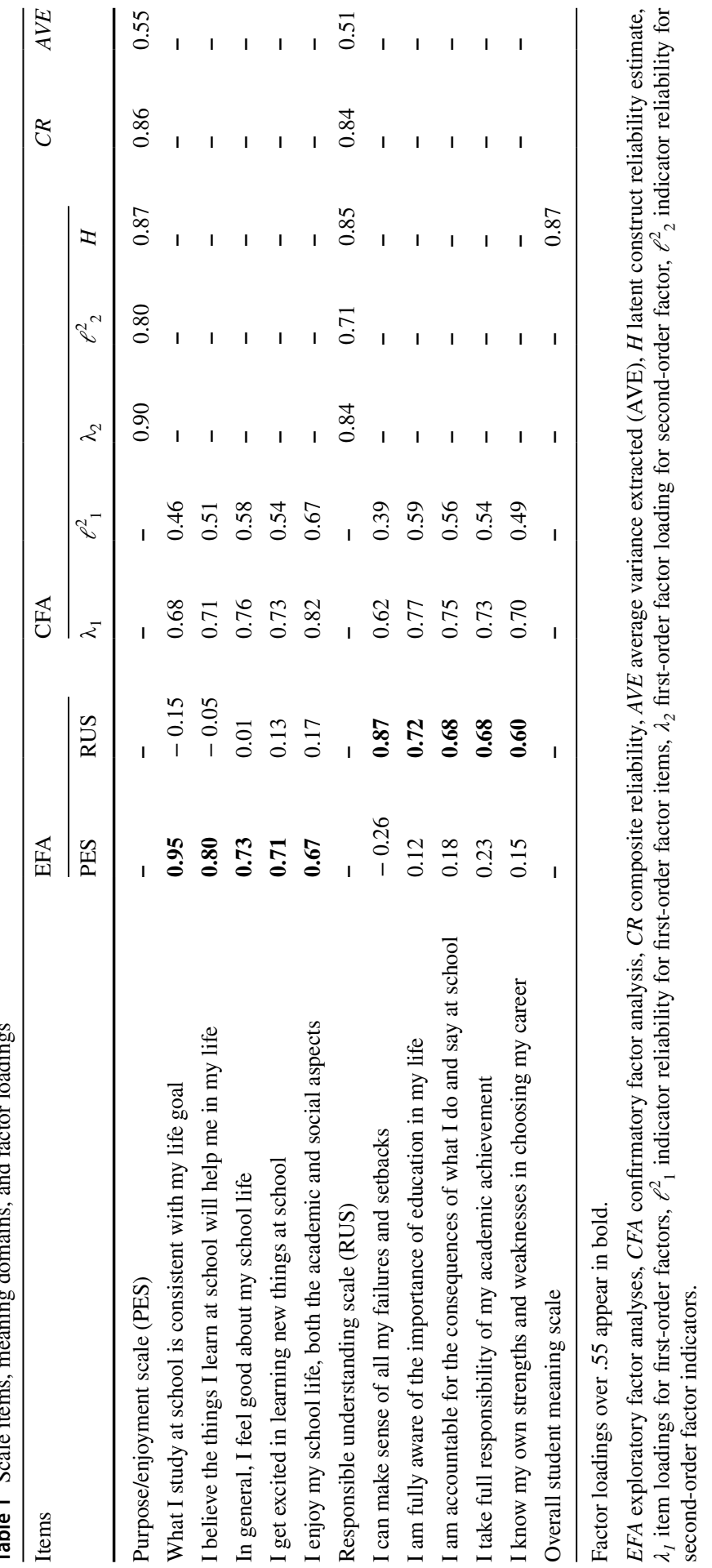




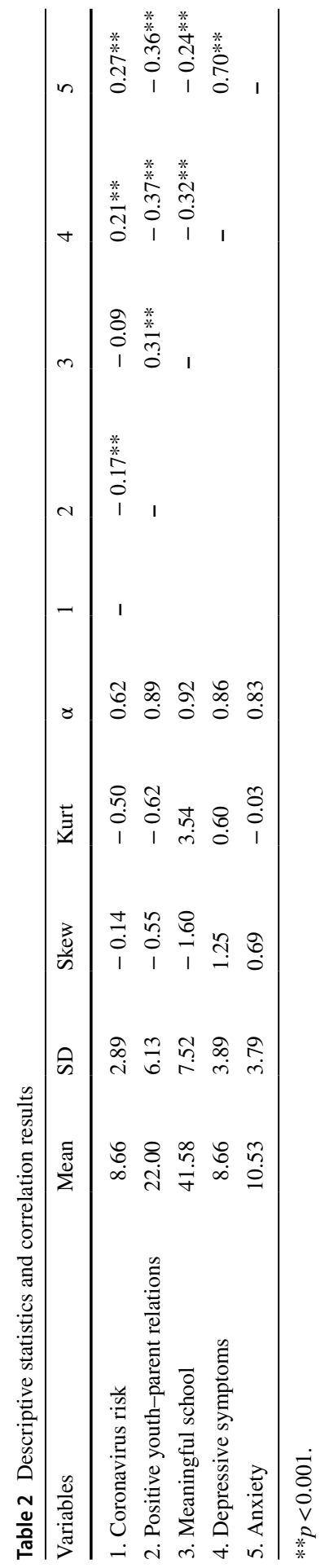


Findings from the reliability analysis also indicated that the measures provided adequate-to-strong internal reliability estimates ( $\alpha$ range $=0.62-0.93$ ).

\subsection{Conditional Process Analysis}

We aimed to examine whether positive youth-parent relationships mitigated in the association between coronavirus risk perception and internalizing problems, and whether a sense of meaning of students moderated the mediating effect of positive youth-parent relationships on this association. To this end, two independent moderated mediation models (i.e., Model 5 and Model 14) were employed to examine the moderating effect of sense of meaning among adolescents, as seen in Fig. 1. Results from conditional process analysis showed that coronavirus risk perception significantly predicted positive youth-parent relationships $(b=-0.35$, $p<0.001)$ and anxiety $(b=0.29, p<0.001)$. Student anxiety was also significantly predicted by positive youth-parent relationships $(b=-0.10, p<0.001)$ and the sense of meaning $(b=-0.09, p<0.001)$. Positive youth-parent relationships mitigated the negative effect of coronavirus risk perception on student anxiety, and meaning moderated the effect of coronavirus risk perception on this problem. The interaction between coronavirus risk and meaning was significant $(b=-0.02$, $p<0.001$ ), as shown in Table 3 . The simple slope effect additionally indicated that the indirect effect of coronavirus risk on anxiety was observed when student sense of meaning was moderate and low $(-1 S D)$, but not when meaning was

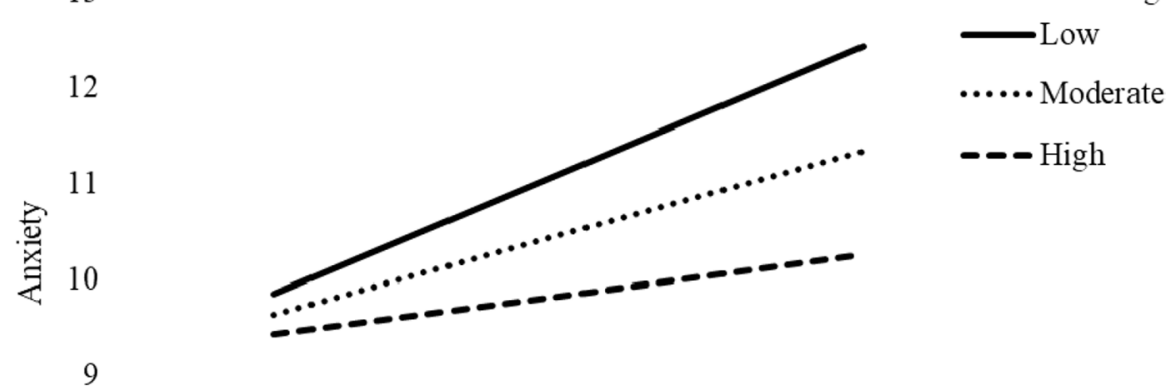

7

Low Moderate High Coronavirus risk perception

Fig. 2 Moderating effect of meaning on the link between coronavirus risk perception and anxiety 
13

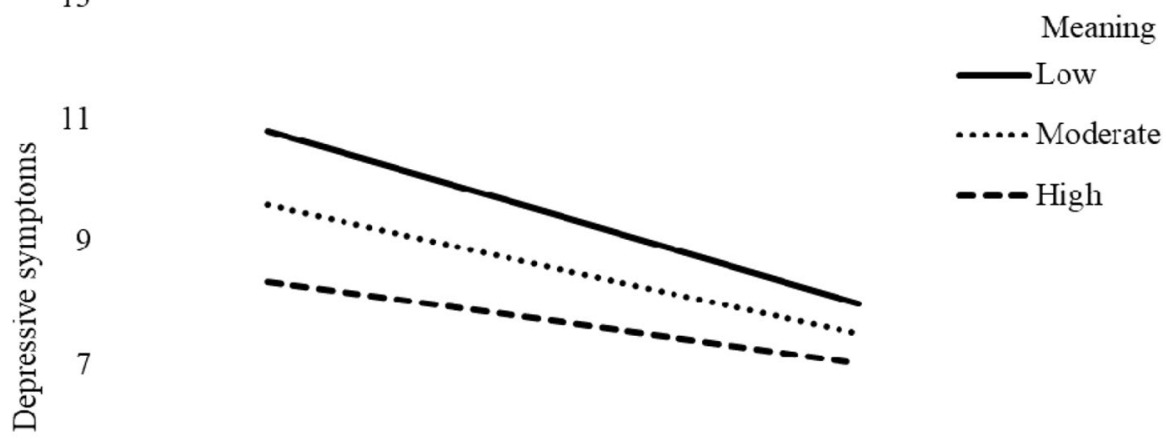

5

3
Low
Moderate
High

Positive youth-parent relationships

Fig. 3 Moderating effect of meaning on the link between positive youth-parent relationships and depressive symptoms

high $(+1 S D)$. These results suggest that meaning in school context serves as a buffer in the face of coronavirus risk and protect youth mental health (Figs. 2, 3).

We next performed another moderated mediation model for depressive symptoms, indicating that coronavirus risk significantly predicted positive youth-parent relationships $(b=-0.35, p<0.001)$ and anxiety $(b=0.19, p<0.001)$. Student anxiety was also significantly predicted by positive youth-parent relationships $(b=-0.17, p<0.001)$ and the sense of meaning $(b=-0.11, p<0.001)$. Positive youth-parent relationships mitigated the negative effect of coronavirus risk perception on student anxiety and meaning moderated the effect of coronavirus risk perception on this problem. The interaction between coronavirus risk and meaning was significant $(b=-0.01, p<0.05)$, as seen in Table 3 . The simple slope effect also reported that the indirect effect of coronavirus risk on depressive symptoms through positive youth-parent relationships was observed when student sense of meaning was high $(+1 S D)$, moderate, and low $(-1 S D)$. These results provide evidence indicating that meaning in school context moderates the effect of positive youth-parent relationship on depressive symptoms of young people.

\section{Discussion}

The purpose of this novel paper was to develop and validate the Meaningful School Questionnaire (MSQ) to assess life meaning in the school context and sought to investigate whether meaningful school moderated the mediating effect of positive youth-parent relationships on the association of the coronavirus risk with 
Table 3 Unstandardized coefficients for the conditional process model of anxiety and depressive symptoms

\begin{tabular}{|c|c|c|c|c|c|c|c|c|}
\hline \multirow[b]{3}{*}{ Antecedent } & & \multicolumn{7}{|c|}{ Consequent } \\
\hline & & \multicolumn{4}{|c|}{$M$ (Positive relations) } & \multicolumn{3}{|c|}{$Y$ (Anxiety) } \\
\hline & \multirow{3}{*}{$a$} & Coeff & $S E$ & $p$ & & Coeff & $S E$ & $p$ \\
\hline$X$ (Coronavirus risk) & & -0.35 & 0.10 & $<0.001$ & $c^{\prime}$ & 0.29 & 0.06 & $<0.001$ \\
\hline$M$ (Positive relations) & & - & - & - & $b_{1}$ & -0.10 & 0.03 & $<0.001$ \\
\hline$W$ (Life meaning) & \multirow{4}{*}{$i_{\mathrm{M} 1}$} & - & - & - & $b_{2}$ & -0.09 & 0.03 & $<0.001$ \\
\hline$X \times W$ & & - & - & - & $b_{3}$ & -0.02 & 0.01 & $<0.001$ \\
\hline \multirow[t]{2}{*}{ Constant } & & 22.01 & 0.31 & $<0.001$ & $i_{\mathrm{y}}$ & 1.04 & 0.73 & 0.001 \\
\hline & & \multicolumn{4}{|c|}{$\begin{array}{l}R^{2}=0.03 \\
F=10.95 ; p<0.001\end{array}$} & \multicolumn{3}{|c|}{$\begin{array}{l}R^{2}=0.16 ; R^{2} \text { change }=0.02 \\
F=17.80 ; p<0.001\end{array}$} \\
\hline
\end{tabular}

Conditional direct effects of coronavirus risk on anxiety

\begin{tabular}{|c|c|c|c|c|c|c|c|c|}
\hline Meaning & & \multicolumn{2}{|l|}{ Coeff } & \multicolumn{2}{|l|}{ BootSE } & \multicolumn{2}{|l|}{ BootLLCI } & BootULCl \\
\hline$M-1 S D(-7.53)$ & & \multicolumn{2}{|l|}{0.45} & \multicolumn{2}{|l|}{0.09} & \multicolumn{2}{|l|}{0.28} & 0.62 \\
\hline$M(0.00)$ & & \multicolumn{2}{|l|}{0.29} & \multicolumn{2}{|l|}{0.06} & 0.17 & \multicolumn{2}{|c|}{0.42} \\
\hline$M+1 S D(7.53)$ & & \multicolumn{2}{|l|}{0.14} & \multicolumn{2}{|l|}{0.08} & -0.02 & \multicolumn{2}{|c|}{0.31} \\
\hline \multirow{2}{*}{\multicolumn{2}{|c|}{ Antecedent }} & \multicolumn{3}{|c|}{$M$ (Positive relations) } & & \multicolumn{3}{|c|}{$Y$ (Depression) } \\
\hline & & Coeff & $S E$ & $p$ & & Coeff & $S E$ & $p$ \\
\hline$X$ (Coronavirus risk) & \multirow[t]{4}{*}{$a$} & -0.35 & 0.10 & $<0.001$ & $c^{\prime}$ & 0.19 & 0.06 & 0.002 \\
\hline$M$ (Positive relations) & & - & - & - & $b_{1}$ & -0.17 & 0.03 & $<0.001$ \\
\hline$W$ (Life meaning) & & - & - & - & $b_{2}$ & -0.11 & 0.02 & $<0.001$ \\
\hline$M \times W$ & & - & - & - & $b_{3}$ & -0.01 & 0.01 & 0.026 \\
\hline \multirow[t]{2}{*}{ Constant } & \multirow[t]{2}{*}{$i_{\mathrm{M} 1}$} & 3.07 & 0.98 & 0.001 & $i_{\mathrm{y}}$ & 6.92 & 0.57 & $<0.001$ \\
\hline & & \multicolumn{4}{|c|}{$\begin{array}{l}R^{2}=0.03 \\
F=10.95 ; p<0.001\end{array}$} & \multicolumn{3}{|c|}{$\begin{array}{l}R^{2}=0.21 ; R^{2} \text { change }=0.01 \\
F=25.76 ; p<0.001\end{array}$} \\
\hline
\end{tabular}

Conditional indirect effects of coronavirus risk on depressive symptoms

\begin{tabular}{lllll}
\hline Meaning & Coeff & BootSE & BootLLCI & BootULCI \\
\hline$M-1 S D(-7.53)$ & 0.08 & 0.03 & 0.03 & 0.16 \\
$M(0.00)$ & 0.06 & 0.02 & 0.02 & 0.11 \\
$M+1 S D(7.53)$ & 0.04 & 0.02 & -0.01 & 0.09 \\
\hline
\end{tabular}

Level of confidence for all confidence intervals in output: $95 \%$; Number of bootstrap samples for percentile bootstrap confidence intervals: 10,000; $W$ (moderator variables) values in conditional tables are the mean and $\pm S D$ from the mean.

internalizing problems. Findings from factor analyses indicated a two-factor solution (purpose-enjoyment and responsible understanding) that comprised of 10 items accounted for approximately $63 \%$ of the variance, with strong factor loading, ranging between 0.60 and 0.95 respectively. Although the scale was designed based on the PURE model (Wong, 2010), proposing a four-factor approach, current results provided a two-factor solution (5 items for each construct: purpose-enjoyment and 
responsible understanding). However, the items of the scale reflect these four structures. Results from confirmatory factor analysis affirm the two-factor measurement model that were indicators of two first-order latent structures, yielding close datamodel fit statistics. The standardized factor loadings of the scale were strong, ranging between 0.62 and 0.82 . The MSQ also provided strong internal and latent construct reliability estimates. Overall, findings from the factor analyses indicate that the MSQ has psychometrically adequate properties for measuring school-specific life meaning among Turkish students.

Secondly, we tested the moderating effect of the meaningful school in the associations between the coronavirus risk perception, youth-parent relationships, and internalizing problems. Results from mediation analyses revealed that positive youth-parent relationships mediated the negative impact of coronavirus risk on anxiety and depressive symptoms. Although coronavirus pandemic has globally affected nearly 1.4 billon students (UNESCO, 2020), little is known how the pandemic effects children and young people's mental health and wellbeing (Cowling et al., 2020). Research indicated that young people highly experienced depression and anxiety compared to prior to pandemic (Xie et al., 2020) and emphasized the effects of the reduction in social interaction and outdoor activities on their mental health (Arslan, 2021; Arslan et al., 2020). Kılınçel et al. (2020) found that homequarantine during pandemic and closure of schools were significant factors that caused anxiety and feelings of loneliness in Turkish adolescents. Some research also indicated that coronavirus risk was associated with lower levels of perceived selfefficacy and higher levels of mental health challenges (Yıldırım \& Güler, 2020).

Additionally, youth-parent relationships was reported to be one of the important contributing factors in various mental health problems (Wang et al., 2014). Research showed that coronavirus pandemic experiences were found significant risk factors in developing mental health problems, negative parent behaviors, and parenting stress, which in turn negatively impacted the quality of youth-parent relationships (Brown et al., 2020; Chung et al., 2020). For example, closures of childcare services, or low family income because of the loss of job can cause that parent experienced significant stress associated with their role of parenting, and this negatively impacts their interactions with children (Chung et al., 2020). The results also showed that positive youth-parent relationships mitigated the adverse impact of coronavirus risk perception on youth internalizing problems. Consistent with the results of the present study, previous research indicated that more positive youth-parent relationships were associated with greater positive social, emotional, and behavioral outcomes (e.g., better peer relationships, prosocial behaviors), which in turn were negatively related to lower children and adolescents' mental health challenges (Buist et al., 2017; Song et al., 2020; Wang et al., 2014). Quality of parenting relationships was associated with various externalizing problems such as antisocial behaviors and deviant peer associations (Wissink et al., 2006). Stein et al. (2020) indicated that positive child-parent relationships explained the links between familism and externalizing symptoms.

Lastly, results from this study demonstrated that meaningful school served as a buffer in the face of coronavirus risk and protected young people's mental health. Life meaning protected youth mental health against the adverse impact of 
coronavirus risk and moderated the effect of positive youth-parent relationships on depressive symptoms of young people. Life meaning is a key to people's mental health and flourishing (Frankl, 1985; Wong, 2016), and this sense help people to overcome challenging circumstances and foster their flourishing by helping them to move beyond a new level of resilience (Wong \& McDonald, 2002). Frankl (1984) has emphasized that search for life meaning is the basic and powerful motivation in person's life and having sense of meaning protects mental health of young people in the case of adverse experiences (Arslan et al., 2020). Similar to the results of this study, previous studies showed that life meaning was significantly and negatively associated with mental health changes, such as depression, anxiety, and distress (Minkkinen et al., 2020; Jim \& Andersen, 2007; Kleftaras \& Psarra, 2012; Zika \& Chamberlain 1992). Young people are more likely to search for more meaning in life (Steger et al., 2011), and low or lack of life meaning, particularly in adolescents, was a risk of experiencing more mental health difficulties and poor physical health (Brassai et al., 2011). Arslan et al. (2020) highlighted that people could still fulfil their lives by focusing on their own essence of searching for life meaning even under adverse life situations. Life meaning in school might facilitate young people' resilience and character strengths and contribute to promoting their psychological health and wellbeing in the context of coronavirus experiences. Thereby, young people with high levels of life meaning have lower levels of internalizing challenges, and this sense can promote their mental health and flourishing in the face of coronavirus experiences.

\subsection{Conclusion and Limitations}

Results from the current study revealed that coronavirus risk had a positive predictive effect on internalizing problems, as well as was a negative predictive of positive youth-parent relationships. Positive youth-parent relationships mitigated the adverse impact of coronavirus risk on the internalizing symptoms of young people. These results suggest that positive youth-parent relationships are an important aspect of developing school-based preventions and interventions. School-based mental health providers could design prevention and intervention strategies not only to improve young people's mental health but also to build up the quality of parent-youth relationships to promote their psychological health. Moreover, the results of this study indicated the protective impact of life meaning in school on young people' mental health in the context of coronavirus experiences. This evidence supports that life meaning is key to foster the psychological health of young people during the pandemic. Thus, meaning-based intervention strategies could be developed to improve youths' sense of life meaning and purpose in the school context, which in turn enhance their resilience to foster their mental health and flourishing. Furthermore, school-based mental health providers could integrate parent-youth experience with the meaning approach to promote positive youth development. These programs could facilitate youths to cope with stressful experiences such as the coronavirus pandemic by promoting their protective and promotive resources. 
Despite these significant for research and practice sketched above, the findings of present study should be considered in light of some methodological libations. Firstly and importantly, this study was conducted using the cross-sectional framework which cannot ascertain a causal association among the variables of the study. Thus, longitudinal designs are warranted to offer additional insights into the relationships between the variables in further studies. Subsequently, self-reported measures are used to collect data in this study that is considered a limitation of the study. Multiple techniques (e.g., qualitative and quantitative) could use in future research for the exploration of the association between the variables in the study. Lastly, the study sample included Turkish adolescents, and future studies could be employed with large and different samples (e.g., young adults). Young people are identified as a non-risk group in terms of coronavirus infection. Therefore, they are less likely to perceive themselves as at risk for coronavirus. During the COVID-19 pandemic, the educational system has also been affected by restriction measures such as temporary school closures worldwide. Therefore, the risk of infection at school is at a minimum level. Meaning in life at school context could be examined by future studies when schools are reopened in different countries.

In conclusion, the results of this study showed that the MSQ is psychometrically sound assessment of measuring meaning in life in school context among young adults. The study of moderated-mediation results suggests that meaningful school moderated the mediating effect of positive youth-parent relations on the association between coronavirus risk and internalizing problems. School-based prevention and interventions programs can be implemented to promote meaningful school which ultimately results in better psychological outcomes of young individuals.

\section{Declarations}

Conflicts of Interest The authors declare that they have no conflicts of interest.

Ethical Approval All procedures performed in studies involving human participants were in accordance with the ethical standards of the institutional and/or national research committee and with the 1964 Helsinki declaration and its later amendments or comparable ethical standards.

Informed Consent Informed consent was obtained from all participants included in the study.

\section{References}

Antonovsky, A. (1987). Unraveling the mystery of health: How people manage stress and stay well. Josey-Bass Ltd.

Arslan, G. (2018a). Social Exclusion, social support and psychological wellbeing at school: A study of mediation and moderation effect. Child Indicators Research, 11(3), 897-918. https://doi.org/10. 1007/s12187-017-9451-1

Arslan, G. (2018b). School-based social exclusion, affective wellbeing, and mental health problems in adolescents: A study of mediator and moderator role of academic self-regulation. Child Indicators Research, 11(3), 963-980. https://doi.org/10.1007/s12187-017-9486-3 
Arslan, G. (2021). Loneliness, college belongingness, subjective vitality, and psychological adjustment during coronavirus pandemic: Development of the College Belongingness Questionnaire. Journal of Positive School Psychology, 5(1), 17-31. https://doi.org/10.47602/jpsp.v5i1.240

Arslan, G., \& Allen, K.-A. (2021). Exploring the association between coronavirus stress, meaning in life, psychological flexibility, and subjective well-being. Psychology, Health and Medicine. https://doi. org/10.1080/13548506.2021.1876892

Arslan, G., \& Yıldırım, M. (2021). Coronavirus stress, meaningful living, optimism, and depressive symptoms: A study of moderated mediation model. Australian Journal of Psychology, 73(2), 113124. https://doi.org/10.1080/00049530.2021.1882273

Arslan, G., Yıldırım, M., Karataş, Z., Kabasakal, Z., \& Kılınç, M. (2020). Meaningful living to promote complete mental health among university students in the context of the COVID-19 pandemic. International Journal of Mental Health and Addiction. https://doi.org/10.1007/s11469-020-00416-8

August, R., \& Dapkewicz, A. (2020). Benefit finding in the COVID-19 pandemic: College students' positive coping strategies. Journal of Positive School Psychology, 5(2), 73-86. https://doi.org/10.47602/ jpsp.v5i2.245

Battista, J., \& Almond, R. (1973). The development of meaning in life. Psychiatry, 36, 409-427.

Brassai, L., Piko, B. F., \& Steger, M. F. (2011a). Meaning in life: Is it a protective factor for adolescents' psychological health? International Journal of Behavioral Medicine, 18(1), 44-51. https://doi.org/ 10.1007/s12529-010-9089-6

Brown, S. M., Doom, J. R., Lechuga-Peña, S., Watamura, S. E., \& Koppels, T. (2020). Stress and parenting during the global COVID-19 pandemic. Child Abuse \& Neglect. https://doi.org/10.1016/j. chiabu.2020.104699

Buist, K. L., Verhoeven, M., Hoksbergen, R., ter Laak, J., Watve, S., \& Paranjpe, A. (2017). Associations of perceived sibling and parent-child relationship quality with internalizing and externalizing problems: Comparing Indian and Dutch early adolescents. The Journal of Early Adolescence, 37(8), 1163-1190. https://doi.org/10.1177/0272431616653473

Burke, J., \& Arslan, G. (2020). Positive education and school psychology during COVID-19 pandemic. Journal of Positive School Psychology, 4(2), 137-139. https://doi.org/10.47602/jpsp.v4i2.243

Caley, P., Philp, D. J., \& McCracken, K. W. J. (2008). Quantifying social distancing arising from pandemic influenza. Journal of the Royal Society Interface, 5(23), 631-639. https://doi.org/10.1098/ rsif.2007.1197

Cauchemez, S., Van Kerkhove, M. D., Archer, B. N., Cetron, M., Cowling, B. J., Grove, P., Hunt, D., Kojouharova, M., Kon, P., Ungchusak, K., \& Oshitani, H. (2014). School closures during the 2009 influenza pandemic: National and local experiences. BMC Infectious Diseases, 14(1), 207. https:// doi.org/10.1186/1471-2334-14-207

Chung, S. K. G., Lanier, P., \& Wong, P. (2020). Mediating effects of parental stress on harsh parenting and parent-child relationship during coronavirus (COVID-19) pandemic in Singapore. Journal of Family Violence. https://doi.org/10.1007/s10896-020-00200-1

Cowling, B. J., Ali, S. T., Ng, T. W., Tsang, T. K., Li, J. C., Fong, M. W., Liao, Q., Kwan, M. Y., Lee, S. L., Chiu, S. S., \& Wu, J. T. (2020). Impact assessment of non-pharmaceutical interventions against COVID-19 and influenza in Hong Kong: An observational study. MedRxiv. https://doi.org/10.1101/ 2020.03.12.20034660

Crumbaugh, J. C., \& Maholick, L. T. (1964). An experimental study in existentialism: The psychometric approach to Frankl's concept of noogenic neurosis. Journal of Clinical Psychology, 20, 200-207. https://doi.org/10.1002/1097-4679(196404)20:2\%3c200::AID-JCLP2270200203\%3e3.0.CO;2-U

Deković, M. (1999). Risk and protective factors in the development of problem behavior during adolescence. Journal of Youth and Adolescence, 28(6), 667-685. https://doi.org/10.1023/A:1021635516 758

Duru, A. G., Uçanok, Z., \& Topçu, A. E. (2014). Olumsuz yaşam olayları, ebeveyn-ergen ilişkisi ve ergenin uyumu arasındaki ilişkilerin aile stres modeli çerçevesinde sınanması: Bir izleme çalışması. Ankara Üniversitesi Bilimsel Araştırmalar Birimi (Proje No: 11B5358001).

Eichelsheim, V. I., Buist, K. L., Deković, M., Wissink, I. B., Frijns, T., Van Lier, P. A., Koot, H. M., \& Meeus, W. H. (2010). Associations among the parent-adolescent relationship, aggression and delinquency in different ethnic groups: A replication across two Dutch samples. Social Psychiatry and Psychiatric Epidemiology, 45(3), 293-300. https://doi.org/10.1007/s00127-009-0071-z

Erdem, S. (2017). Attachment to parents and resilience among high school students. Journal of Positive School Psychology, 1(1), 22-33. Retrieved from https://journalppw.com/index.php/JPPW/article/ view/3. Accessed 30 July 2021 
Field, A. (2009). Discovering statistics using SPSS. Sage publications.

Frankl, V. E. (1984). The unheard cry for meaning: Psychotherapy and humanism. Washington Square Press.

Frank1, V. E. (1985). Man's search for meaning. Simon and Schuster.

Frankl, V. E. (1992). Man's search for meaning: An introduction to logotherapy. Beacon Press.

Genç, E., \& Arslan, G. (2021). Optimism and dispositional hope to promote college students' subjective well-being in the context of the COVID-19 pandemic. Journal of Positive School Psychology, 5(2), 87-96. https://doi.org/10.47602/jpsp.v5i2.255

Glaw, X., Kable, A., Hazelton, M., \& Inder, K. (2017). Meaning in life and meaning of life in mental health care: An integrative literature review. Issues in mental health nursing, 38(3), 243-252.

Hayes, A. F. (2018). Introduction to mediation, moderation, and conditional process analysis: A regression-based approach. Guilford Press.

Hooper, D., Coughlan, J., \& Mullen, M. R. (2008). Structural equation modelling: Guidelines for determining model fit. Electronic Journal of Business Research Methods, 6(1), 53-60.

Jim, H. S., \& Andersen, B. L. (2007). Meaning in life mediates the relationship between social and physical functioning and distress in cancer survivors. British Journal of Health Psychology, 12(3), 363-381. https://doi.org/10.1348/135910706X128278

Kılınçel, Ş, Kılınçel, O., Muratdağı, G., Aydın, A., \& Usta, M. B. (2020). Factors affecting the anxiety levels of adolescents in home-quarantine during COVID-19 pandemic in Turkey. Asia-Pacific Psychiatry, 13, e12406. https://doi.org/10.1111/appy.12406

Kleftaras, G., \& Psarra, E. (2012). Meaning in life, psychological well-being and depressive symptomatology: A comparative study. Psychology, 3(04), 337-345. https://doi.org/10.4236/psych. 2012.34048

Kline, R. B. (2015). Principles and practice of structural equation modeling. Guilford.

Leppin, A., \& Aro, A. R. (2009). Risk perceptions related to SARS and avian influenza: Theoretical foundations of current empirical research. International Journal of Behavioral Medicine, 16(1), 7-29. https://doi.org/10.1007/s12529-008-9002-8

Loades, M. E., Chatburn, E., Higson-Sweeney, N., Reynolds, S., Shafran, R., Brigden, A., Linney, C., McManus, M. N., Borwick, C., \& Crawley, E. (2020). Rapid systematic review: The impact of social isolation and loneliness on the mental health of children and adolescents in the context of COVID-19. Journal of the American Academy of Child \& Adolescent Psychiatry., 59(11), 1218-1239. https://doi.org/10.1016/j.jaac.2020.05.009

Luthar, S. S., Cicchetti, D., \& Becker, B. (2000). The Construct of resilience: A critical evaluation and guidelines for future work. Child Development, 71(3), 543-562. https://doi.org/10.1111/ 1467-8624.00164

Masten, A. S. (2014). Ordinary magic: Resilience in development. Guilford Press.

Minkkinen, J., Auvinen, E., \& Mauno, S. (2020). Meaningful work protects teachers' self-rated health under stressors. Journal of Positive School Psychology, 4(2), 140-152. https://doi.org/10.47602/ jpsp.v4i2.209

O'Connor, B. P. (2000). SPSS and SAS programs for determining the number of components using parallel analysis and Velicer's MAP test. Behavior Research Methods, Instruments, and Computers., 32, 396-402. https://doi.org/10.3758/BF03200807

Platsidou, M., \& Daniilidou, A. (2021). Meaning in life and resilience among teachers. Journal of Positive School Psychology, 5(2), 97-109. https://doi.org/10.47602/jpsp.v5i2.259

Preacher, K. J., \& Hayes, A. F. (2008). Asymptotic and resampling strategies for assessing and comparing indirect effects in multiple mediator models. Behavior Research Methods, 40(3), 879891. https://doi.org/10.3758/BRM.40.3.879

Preacher, K. J., Rucker, D. D., \& Hayes, A. F. (2007). Addressing moderated mediation hypotheses: Theory, methods, and prescriptions. Multivariate Behavioral Research., 42(1), 185-227. https:// doi.org/10.1080/00273170701341316

Renn, O., \& Rohrmann, B. (2000). Cross-cultural risk perception research: State and challenges. In O. Renn \& B. Rohrmann (Eds.), Cross-cultural risk perception. A survey of empirical studies. Springer.

Slovic, P. (1987). Perception of risk. Science, 236(4799), 280-285. https://doi.org/10.1126/science. 3563507

Slovic, P., Fischhoff, B., \& Lichtenstein, S. (1982). Why study risk perception? Risk Analysis, 2(2), 83-93. https://doi.org/10.1111/j.1539-6924.1982.tb01369.x 
Song, J., Ma, C., \& Ruan, Y. (2020). Left-behind children's grandparent-child and parent-child relationships and loneliness: A multivariable mediation model. Family Relations. https://doi.org/10. 1111/fare. 12480

Steger, M. F., Frazier, P., Oishi, S., \& Kaler, M. (2006). The meaning in life questionnaire: Assessing the presence of and search for meaning in life. Journal of Counseling Psychology, 53, 80-93. https:// doi.org/10.1037/0022-0167.53.1.80

Steger, M. F., Oishi, S., \& Kesebir, S. (2011). Is a life without meaning satisfying? The moderating role of the search for meaning in satisfaction with life judgments. The Journal of Positive Psychology, 6(3), 173-180. https://doi.org/10.1080/17439760.2011.569171

Stein, G. L., Mejia, Y., Gonzalez, L. M., Kiang, L., \& Supple, A. J. (2020). Familism in action in an emerging immigrant community: An examination of indirect effects in early adolescence. Developmental Psychology, 56(8), 1475-1483. https://doi.org/10.1037/dev0000791

Stevens, J. P. (2009). Applied multivariate statistics for the social sciences. Routledge.

Tabachnick, B. G., \& Fidell, L. S. (2013). Using multivariate statistics (6th ed.). Pearson.

United Nations Educational, Scientific and Cultural Organization. (2020). COVID-19 Impact on Education. https://en.unesco.org/covid19/educationresponse.

Wang, J. N., Liu, L., \& Wang, L. (2014). Prevalence and associated factors of emotional and behavioural problems in Chinese school adolescents: A cross-sectional survey. Child: Care, Health and Development, 40(3), 319-326. https://doi.org/10.1111/cch.12101

Wissink, I. B., Dekovic, M., \& Meijer, A. M. (2006). Parenting behavior, quality of the parent-adolescent relationship, and adolescent functioning in four ethnic groups. The Journal of Early Adolescence, 26(2), 133-159. https://doi.org/10.1177/0272431605285718

Wong, P. T. P. (1998). Implicit theories of meaningful life and the development of the Personal Meaning Profile (PMP). In P. T. P. Wong \& P. S. Fry (Eds.), The human quest for meaning: A handbook of psychological research and clinical applications. Erlbaum.

Wong, P. T. P. (2010). The PURE strategy to create lean and excellent organizations. International Journal of Existential Psychology and Psychotherapy, 3(2), 1-21.

Wong, P. T. P. (2011). Positive psychology 2.0: Towards a balanced interactive model of the good life. Canadian Psychology, 52(2), 69-81.

Wong, P. T. P. (2016). Meaning-seeking, self-transcendence, and wellbeing. In A. Batthyany (Ed.), Logotherapy and existential analysis: Proceedings of the Viktor Frankl Institute (Vol. 1; pp. 311-322). Springer.

Wong, P. T. P., \& McDonald, M. (2002). Tragic optimism and personal meaning in counselling victims of abuse. Pastoral Sciences, 20(2), 231-249.

Wong, P. T. P., \& Wong, L. C. J. (2012). A meaning-centered approach to building youth resilience. In The human quest for meaning: Theories, research, and applications, 2nd ed. (pp. 585-617). Routledge/Taylor \& Francis Group.

Xie, X., Xue, Q., Zhou, Y., Zhu, K., Liu, Q., Zhang, J., \& Song, R. (2020). Mental health status among children in home confinement during the coronavirus disease 2019 outbreak in Hubei Province, China. JAMA Pediatrics, 174(9), 898-900. https://doi.org/10.1001/jamapediatrics.2020.1619

Yıldırım, M., \& Güler, A. (2020). Factor analysis of the COVID-19 perceived risk scale: A preliminary study. Death Studies. https://doi.org/10.1080/07481187.2020.1784311

Yıldırım, M., Arslan, G., \& Wong, P. T. (2021). Meaningful living, resilience, affective balance, and psychological health problems among Turkish young adults during coronavirus pandemic. Current Psychology. https://doi.org/10.1007/s12144-020-01244-8

Zhang, J., Lu, H., Zeng, H., Zhang, S., Du, Q., Jiang, T., \& Du, B. (2020). The differential psychological distress of populations affected by the COVID-19 pandemic. Brain, Behavior, and Immunity, 87, 49-50. https://doi.org/10.1016/j.bbi.2020.04.031

Zika, S., \& Chamberlain, K. (1992). On the relation between meaning in life and psychological wellbeing. British journal of psychology, 83(1), 133-145.

Publisher's Note Springer Nature remains neutral with regard to jurisdictional claims in published maps and institutional affiliations. 